\title{
C) Hitson
}

\section{Negócio da China: a relação entre mídia e poder na diplomacia do Governo Geisel (1974-1979)}

\author{
China Business: the relation between media and power in the Geisel Government \\ Diplomacy (1974-1979)
}

\section{Pricila Niches Müller"}

Resumo: Este trabalho aborda relações entre imprensa e política externa no Brasil, com foco na análise do posicionamento de órgãos da imprensa a respeito da política externa do governo Geisel (1974-1979), a qual buscou a diversificação de parcerias com o emprego de uma política dita "pragmática, responsável e ecumênica", com ênfase no estabelecimento inicial da parceria estratégica com a República Popular da China (RPC), inclusive instalando Embaixadas em ambos os países. Assim, o objetivo principal do estudo é investigar de que maneira a formação de parceria entre Brasil e China está retratada na grande imprensa brasileira no contexto dos anos que compreendem o Governo Geisel, sendo neste artigo abordado especificamente sobre a representação feita pela imprensa acerca da posse do General Ernesto Geisel e a política externa do governo, bem como uma análise da questão que envolve a imprensa e a "opinião pública". O estudo foi construído com base em bibliografia especializada e na análise da documentação de dois dos maiores veículos de comunicação impressa da época: O Estado de São Paulo e o Jornal do Brasil. É importante ressaltar que este estudo faz parte de um trabalho maior acerca do assunto, desenvolvido em minha dissertação de mestrado pelo PPGH da PUCRS.

Palavras-chave: Governo Geisel. Jornal do Brasil. O Estado de São Paulo. "Opinião Pública". Brasil-China.

Abstract: This paper deals with relations between the press and foreign policy in Brazil, focusing on the analysis of the position of press agencies regarding the foreign policy of the Geisel government (1974-1979), which sought to diversify partnerships with the employment of a so-called "pragmatic, responsible and ecumenical" policy, with emphasis on the initial

\footnotetext{
" Doutoranda CNPq em História pelo Programa de Pós-Graduação em História da Pontifícia Universidade Católica do Rio Grande do Sul. Contato: pricila.muller89@gmail.com
} 


\section{C) GitcastóricA}

establishment of the strategic partnership with the China Popular Republic, including at embassies level between both countries. Thus, the main objective of the study is to investigate how the formation of partnership between Brazil and China is portrayed in the mainstream Brazilian press in the context of the years that comprise the Geisel Government. This article deals specifically with the representation made by the press about Presidential Inauguration. Ernesto Geisel and the government's foreign policy, as well as an analysis of the issue involving the press and "public opinion". The study was based on specialized literature and documentation analysis of two of the largest print media of the time: The State of São Paulo and Jornal do Brasil. It is important to emphasize that this study is part of a larger work on the subject, developed in my master's dissertation by PUCRS PPGH.

Keywords: Government Geisel. Jornal do Brasil. O Estado de São Paulo. "Public opinion". BrazilChina.

\section{Introdução}

Neste artigo, considerando a mídia impressa como um importante vetor social, procurou-se identificar como se construía nos jornais e se já era possível perceber o caráter estratégico $^{\mathrm{I}}$, no processo embrionário da parceria entre Brasil e China através da política externa brasileira, tal qual a bibliografia especializada costuma empregar para abordar a relação entre ambos na década de $1990^{2}$. No entanto, acredita-se que a expressão pode ser usada para referenciar acordos anteriores a esse período, como o estudado nesta pesquisa. Tal hipótese surgiu por se tratar de uma parceria firmada no período da ditadura civilmilitar³ (1964-1985) no Brasil, tendo como uma das características o combate ao comunismo

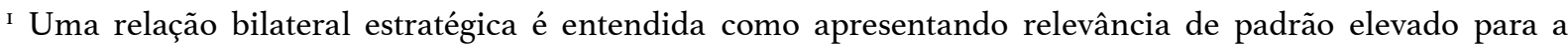
realização de objetivos de médio e longo prazo da política externa de um país, considerando a noção hegemônica de interesse nacional que neste se apresente.

${ }^{2}$ Sobre isso, ver os trabalhos de Henrique Altemani de Oliveira, Letícia Pinheiro e Danielly Becard.

3 Conforme Tatyana de Amaral Maia (2013) "A partir de 2000, com a publicação do livro Ditadura militar, esquerdas e sociedade, de Daniel Aarão Reis, as pesquisas tomaram um novo impulso e incorporaram às suas análises as complexas relações estabelecidas entre civis e militares naqueles tortuosos anos. Nesta perspectiva, a ditadura não seria exclusivamente militar, fruto da truculência e do autoritarismo gestados na caserna e impostos a toda a sociedade a partir de 1964. Ao contrário, diversos setores da sociedade civil aplaudiram o golpe que derrubou o presidente João Goulart; promoveram manifestações entusiásticas em favor da intervenção militar e ingressaram nas fileiras estatais para propor projetos de desenvolvimento para a nação. É neste sentido que o artigo incorpora a perspectiva de que se trata de um regime civil-militar. A ditadura, composta e legitimada também pela participação de civis, se guiou por projetos gestados por estes antes mesmo do golpe de 1964. Durante o processo de redemocratização, iniciado em 1974, elaborou-se uma memória de resistência que apresenta os civis como defensores incontestes da democracia, mas se silenciaram as relações de apoio, participação e legitimidade de vários setores da sociedade durante os 2I anos do regime." (p. I84-I85). Caracterizou-se assim o caráter civil-militar do regime ditatorial, no qual, apesar da "última palavra" ser do
} 


\section{C) Hitsoa}

no país, bem como a intenção de não deixar que tal ideologia se propagasse pelas Américas ${ }^{4}$, conforme também era o intuito dos Estados Unidos, país pelo qual o Brasil possuiu um alinhamento ideológico em boa parte de sua história.

Em meados da década de 1960, a política externa brasileira (PEB) sofreu uma mudança de paradigmas e passou a buscar outros parceiros políticos e econômicos. Essa inserção do Brasil em um contexto mais global refletiu-se também no meio acadêmico. É nesta perspectiva que entram em cena as relações com países asiáticos; primeiramente, com o Japão, nas décadas de I960 e I970; posteriormente, com a China, a partir da segunda metade dos anos 1970; e com outros países como a Coreia do Sul, o relacionamento é ainda mais recente.

Em meados dos anos 1980, houve uma crise nas relações diplomáticas entre Brasil e Ásia, sendo estas retomadas com maior fluxo nos anos 990 (OLIVEIRA; MASIERO, 2005). Em I96I, o então vice-presidente João Goulart esteve na China, realizando uma visita diplomática que foi interrompida pela renúncia do Presidente Jânio Quadros. Para os militares, que faziam suposições sobre vínculos entre o vice-presidente e o Partido Comunista, Jango era visto, de certa forma, como uma ameaça ao país. Nesse sentido, é importante lembrar que, por ocasião do Golpe Civil-Militar de 1964 no Brasil, a China representava o perigo comunista e, por isso, não ocorreram relações sino-brasileiras durante o auge da ditadura civil-militar. Conforme Celso Lafer (200I), havia no Brasil um nacionalismo de inspiração militar baseado no desenvolvimento e na integração do espaço nacional, que buscava formular a sua identidade internacional, mas sem ser um nacionalismo de característica expansionista.

Além disso, outra característica que influenciou o questionamento nesta pesquisa quanto ao caráter estratégico da formação de parceria foi a adoção de uma política externa "pragmática, responsável e ecumênica" por parte do Governo Geisel, em que se percebe um distanciamento das práticas diplomáticas realizadas desde o golpe civil-militar de 1964. Tal maneira de conduzir a política externa também já foi analisada por outros autores ${ }^{5}$ através de suas congruências com a Política Externa Independente (PEI), praticada no governo que precedeu a ditadura civil-militar. Considerando estudos sobre o tema, esta investigação propõe uma ampliação da abordagem ao relacioná-lo à forma como a imprensa caracterizou

\footnotetext{
ditador ocupando o cargo de presidente, ele não governou sozinho o país, ao contrário do que propõe FICO (20I4) ao ressaltar que o golpe havia sido civil-militar, porém o governo teria caráter essencialmente militar. 4 Com exceção da Guiana, desde a década de 1950, todos os países da América do Sul sofreram processos ditatoriais. O último a findar foi o do Chile, em 1990.

5 Ver LIGIÉRO (20II).
} 


\section{G) Citceátórica}

a ação governamental na sua política externa, visto que os engajamentos externos afetam diretamente o plano interno de um país, especialmente na parceria entre Brasil e China. Através disso, buscou-se apresentar uma comparação entre a postura do governo Geisel quanto à PEB e a de governos ditatoriais anteriores ao seu e, para isso, a observação à imprensa aqui selecionada para análise foi crucial quanto às narrativas que os dois jornais utilizaram para noticiar os caminhos para o estabelecimento de relações diplomáticas entre o Brasil e a China comunista. É oportuno lembrar que, na época, o Brasil já era parceiro da outra China, a nacionalista, e também que, logo após o golpe civil-militar, ocorreram prisões de chineses provenientes da China comunista aqui no Brasil, acusados de subversão, mas que aqui estavam por questões comerciais ${ }^{6}$.

\section{Negócio da China}

A expressão popular "negócio da China" intitula este artigo por todo o sentido que ela representa de "um negócio vantajoso", expressão que também era usada em anúncios de mercadorias encontrados nas páginas do Jornal do $\mathrm{Brasil}^{7}$, no período pesquisado, mas que, na sua maioria, antecederam o estabelecimento de relações diplomáticas entre Brasil e China, que é o foco deste artigo.

Se for realizada uma rápida pesquisa, encontra-se relacionado à origem da expressão desde o tempo das viagens de Marco Polo, que, ao fazer a descrição dos lugares que visitava, atraiu o interesse de europeus, por exemplo, que buscavam maneiras de enriquecer o comércio. Neste artigo, o que notamos é semelhante, pois os eventos selecionados para a análise, nos periódicos, têm justamente o propósito de expandir o comércio internacional.

Nosso interesse está em aprofundar a construção narrativa que a imprensa, aqui representada pelo Jornal do Brasil e O Estado de São Paulo, fez sobre a parceria que se anunciava no início do Governo Geisel, tendo como eventos-chave de pesquisa a posse do

\footnotetext{
${ }^{6} \mathrm{O}$ relacionamento conturbado entre as "duas Chinas" cabe também no contexto da Guerra-Fria, assim como o relacionamento delas com a URSS e os EUA. Nos anos I97o, há uma aproximação dos EUA com a RPC e uma intensificação dos atritos entre URSS e a China comunista. A título de conhecimento, estas situações também estavam presentes nas discussões das editorias de internacional dos periódicos analisados nesta pesquisa, mas não é objetivo deste trabalho analisá-las. Quanto a bibliografia ver: DOMINGOS (2010), HOBSBAWM (1995), OLIVEIRA (2006) e PINTO (2000).

${ }^{7}$ No jornal $O$ Estado de São Paulo, não identificamos, durante a parte de coleta de material para a pesquisa, propagandas que mencionassem produtos sendo vendidos e que fizessem referência à China. Já no Jornal do Brasil, há uma série de publicidades e propagandas, desde produtos que não tenham nada a ver com a China, mas se utilizam da expressão "Negócio da China", como pacotes de viagens para aquele país, publicidades estas que se intensificam na medida em que avançam as relações entre os dois países.
} 


\section{C) Hitsơ TórICA}

General presidente. Consideramos a formação e defesa de uma "opinião pública"8 por parte dos periódicos, ora em comum acordo com o governo, ora questionadora. As diferenças aparecem não somente entre as duas empresas jornalísticas, como é possível observar, mas também a abordagem individual dos jornais manifestou oscilação.

Assim como os moldes habermasianos apresentam, é de grande importância ao leitor saber que o conceito de opinião trata de reputação, de considerar aquilo que se é colocado e que está na opinião do outro. Conforme o dicionário, é um substantivo feminino que significa a maneira de pensar, de ver e de julgar.

Ainda Habermas ${ }^{9}$ discute a questão de uma mudança estrutural na esfera pública, preocupando-se com o dilema do intervencionismo. Se o Estado intervém, ele perpassa a esfera pública. Porém, as empresas também são uma ameaça, pois quando elas controlam a economia, vão tentar controlar a esfera pública e também interferir na esfera política. Há, nesse contexto, uma mudança entre produtor e consumidor, ocorrendo uma ampliação neste último, principalmente em relação à cultura. Habermas fala em publicidade, propaganda e manipulação culturais utilizadas pelos setores políticos e econômicos para envolver os indivíduos.

A opinião pública provém das pessoas instruídas e se expande "principalmente entre aquelas classes que, quando atuam em massa, constituem o que prepondera" /50/. Certamente aí não pertencem "as classes mais baixas do povo", os sans-culottes, pois, sob a pressão da necessidade e do trabalho, não tem disposição nem oportunidade "de se preocuparem com coisas que não concernem de modo imediato o seu bemestar corpóreo" /5I/. (HABERMAS, 1984, p. 125-I26)

\footnotetext{
${ }^{8}$ Apesar de a expressão parecer significar algo grandioso, remetendo às massas, defendemos neste trabalho que esta influência vinha de grupos menores. Conforme Champagne "[...] até o início dos anos 6o, os estudos sobre a opinião que eram efetuados pelos especialistas da ciência política partiam de alguma forma da definição - dominante, na época, do ponto de vista social - da opinião pública: em grande parte, incidiam sobre os "grupos de pressão" e consistiam no estudo das estratégias dessas minorias ativas e organizadas (lobbies) que tentavam influenciar as instâncias políticas (parlamento e governo) ao fabricarem, em particular, por meio de campanhas de imprensa, movimentos de "opinião", mais ou menos artificiais.". (CHAMPAGNE, I998, p. 8I) ${ }_{9}^{9}$ Habermas expõe a visão daqueles intelectuais mencionados no primeiro capítulo, sobre a questão da opinião pública, cada qual com seu ponto de vista. Kant considera que os filósofos são os mais qualificados para serem porta-vozes da opinião pública, e isso pressupõe um uso público da razão, uma necessidade racional dos atos do poder serem públicos. Hegel e Marx discordam da visão de Kant, pois, para eles, isso não é opinião pública, mas apenas a opinião de um público, sem constituir unidade. Mill e Tocqueville questionam a explicação dos três anteriores, em favor de um senso comum mais realista, ampliado através da imprensa, sendo a opinião pública apenas uma força entre outras forças e as massas sem serem ouvidas. Habermas conclui, por fim, que a esfera pública se amplia enquanto esfera, esvaziando o setor privado (HABERMAS, 1984, p. 168).
} 


\section{C) Hitson}

Por vinte e um anos, o Brasil esteve sob um regime autoritário, governado por militares. É tradicional pensar em uma influência que a política tem em relação à imprensa nesse período, em virtude do golpe militar ocorrido em 1964, ao passo que a imprensa sofreu deveras retaliações acerca do que era publicado pela mídia em geral. Tendo em vista o significado de público como um conjunto de indivíduos, com suas vidas privadas e pertencentes a uma sociedade, relacionando-se econômica e politicamente sob uma constante influência de setores empresariais e estatais detentores do poder, a realidade de uma "opinião pública" ainda é algo a ser questionado. E, considerando que ela exista, teria ainda que ser investigado de que indivíduos ela é composta pois, como evidenciamos no trecho citado de Habermas, alguns cidadãos não dispõem de tempo para lidar com assuntos que não digam respeito exclusivamente ao seu bem-estar, ao mesmo tempo em que nem todos se interessam pelo que ocorre mundo afora, preocupando-se apenas com o seu círculo social. Visto que os acontecimentos publicados na cena pública são meticulosamente escolhidos de acordo com interesses privados, analisaremos aqui a sua repercussão na mídia impressa selecionada.

Com base no artigo de Bourdieu (1982), podemos refletir de uma maneira ampla sobre o papel de cada indivíduo na sociedade, desde a sua representação individual e o papel que ele exerce na economia e na política, até o inverso, de como as instituições políticas, o Estado e também as empresas podem interferir na vida privada do homem. Em meio a esses aspectos, temos também o papel da imprensa e, com ela, também a expressão "opinião pública". É uma imprensa que foi conquistando o seu espaço, construindo um público leitor cativo e com ele os patrocinadores interessados nesse público. E é ainda uma esfera pública que foi sendo ampliada e tendo o seu caráter de público misturado entre setores da sociedade, reduzindo o privado.

O questionamento que fica é o seguinte: como pensar uma “opinião pública" em meio a tantas demonstrações de poder político, social e econômico? Seria realmente possível haver uma opinião que deveras represente algo unificadamente? Podemos dizer que esses poderes estão difundidos nos diversos meios de comunicação, tentando cativar o indivíduo, assim como o jornal o fez para construir o seu público leitor.

\section{A mídia e a posse do pragmatismo responsável e ecumênico}

Desde que o General Ernesto Geisel iniciou as preparações para o seu governo, esperava-se que, com ele, viriam muitas transformações, principalmente na área política. 


\section{C) GitcastóricA}

Seu discurso ${ }^{\text {IO }}$ de posse é comparável ao do presidente General Garrastazu Médici, que o antecedeu, porém ambos diferem consideravelmente dos dois primeiros presidentes militares da ditadura civil-militar instaurada em 1964. A questão do apelo a Deus, a NaçãoIIe a união do povo brasileiro era unânime em todos. O terceiro e o quarto presidente militar da ditadura civil-militar destoavam no aspecto de ressaltar um maior interesse em se relacionar economicamente em caráter mundial e sobre o fator ideológico ${ }^{12}$ não ser motivo de empecilho nestas relações.

Essa postura ficou evidenciada, principalmente, com Geisel e o ministro do exterior Azeredo da Silveira, que nomearam sua política externa de pragmática, responsável e ecumênica. O que fazia dela uma política supostamente livre de compromisso ideológico, mas responsável por controlar quem eram os seus agentes (PINHEIRO, 1993). Assim como se anunciava no discurso e como é abordado pela bibliografia especializada, os jornais mostravam em suas páginas os sinais de uma transformação no modo de agir do governo que estava assumindo o poder, mesmo que de maneira incerta e especulativa, pois não havia nenhuma data marcada para que as mudanças ocorressem.

No jornal OESP, foi publicado um texto de opinião ${ }^{13}$ entre os editoriais ${ }^{\mathrm{I}}$, intitulado "Chegou a hora das definições", no dia seguinte à posse de Geisel, I6 de março de I974. No texto, consta que

[..] Um governo que assume tem sempre de si um espaço em branco a ocupar, toda uma área de poder a ser exercida. E, nas mudanças, não se trocam apenas os homens, mas também os estilos. Ora, todas as indicações coincidem na de que estamos às vésperas de uma profunda transformação, de dimensões que não podem ser precisamente avaliadas e que reclamarão tempo para que possam ser analisadas. ${ }^{15}$

\footnotetext{
Io Discursos do Ex-Presidente General Ernesto Geisel estão disponíveis na biblioteca on-line da presidência: http://www.biblioteca.presidencia.gov.br/presidencia/ex-presidentes/ernesto-geisel Acesso em: OI/I2/20I7.

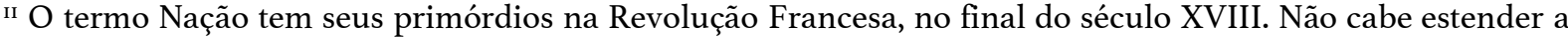
discussão para os propósitos deste trabalho. Sobre isso ver: ANDERSON, Benedict; FICHTE, Johann G.; RENAN, Ernest; SMITH, Antony; e outros.

${ }^{12}$ Não cabe estender a discussão para os propósitos desta pesquisa.

I3 "Chegou a hora das definições", O Estado de São Paulo, I6 de março de i974, p. 3, editorial.

I4 Conforme KRILOW (2018) analisa, mencionando as definições sobre os jargões jornalísticos feitas por Aguiar, considera-se "editorial como o espaço privilegiado, mas não único, de expressão do que deveria ser considerado o ponto de vista oficial do jornal e/ou da redação, é um texto analítico que não possui assinatura”. AGUIAR, Rafe. Dicionário Jornalístico: entenda todos os jargões. Coisas de Jornalista, 20I6. apud KRILOW, L. S. W. Cidades de papel: as representações sobre as favelas na imprensa carioca durante o segundo governo Vargas (I95I-I954). Dissertação de mestrado. Porto Alegre: PUCRS, 2018.

I5 "Chegou a hora das definições", O Estado de São Paulo, I6 de março de 1974, p. 3, editorial.
} 


\section{C) Histea TórICA}

O periódico ressalta ainda no mesmo texto, na sequência, a demonstração de uma postura forte por parte do presidente recém-empossado, que comandaria o governo sem delegar suas decisões para outros representantes do governo.

Enquanto o OESP assim se manifestava, o Jornal do Brasil optou por destacar a fala do próprio Ministro do Exterior Azeredo da Silveira, neste mesmo dia, em uma notícia ${ }^{16}$ composta de uma foto acima do título "Silveira quer fortalecer relações com a A. Latina", na editoria que trata sobre a sucessão presidencial. Apesar de o título estar destacando a América Latina, na notícia, ela é mencionada apenas no primeiro e no último parágrafo. A essência do conteúdo volta-se para o tema das mudanças necessárias no rumo da política externa, também explorando os aspectos das transformações que se esperavam do novo governo. A narrativa do escrito assinala, a respeito da fala do Ministro, que, naquele momento (1974), o Brasil não poderia ficar alheio às outras nações, sendo o seu intuito desenvolver-se e adquirir maior representatividade no plano internacional ${ }^{17}$.

Para Geisel, o desenvolvimento nacional estava conectado diretamente à capacidade energética ${ }^{18} \mathrm{e}$, esse foi um tópico recorrente no seu governo, sendo inclusive um dos motivos de impasse entre Brasil e Estados Unidos na ocasião em que ocorreu o Acordo entre Brasil e Alemanha sobre a energia nuclear. Shigeaki Ueki ${ }^{19}$ era o responsável escolhido pelo então presidente para o Ministério de Minas e Energia. Nesse contexto, um projeto que já estava em negociação antes do mandato de Geisel era a construção da Usina Hidrelétrica de Itaipu, localizada no Rio Paraná e que faz a fronteira entre Brasil e Paraguai, resultado de uma parceria entre os dois países. A construção da usina foi iniciada no segundo ano do Governo Geisel, mas sua inauguração foi realizada somente no final do governo seguinte.

Outra fonte de energia, porém não renovável, e que gera crises que repercutem mundialmente é o petróleo. Uma das crises ocorreu em 1973 e produziu impacto ainda no período do Governo aqui em análise, o que também refletiu no fim do "milagre

\footnotetext{
I6 "Silveira quer fortalecer relações com a A. Latina", Jornal do Brasil, I6 de março de I974, p. I3, Iº caderno.

${ }^{17}$ Em entrevista, Geisel falou a respeito da política externa dos governos anteriores, que, na sua opinião, servia demasiadamente aos interesses dos Estados Unidos. Essa era uma atuação que Geisel desejou mudar, segundo sua entrevista, para buscar mais independência, projetando-se para outros países e na medida do possível tratar os EUA de igual para igual (D'ARAÚJO\&CASTRO, I997, p. 335-336).

${ }^{18} \mathrm{Na}$ mesma entrevista, Geisel, ao ser questionado sobre como se projeta o desenvolvimento de um país, entre outros aspectos, menciona que "[...] Outro setor prioritário era o de energia elétrica. Um país que não tem energia elétrica não pode crescer, não pode se desenvolver, inclusive na zona rural. A energia elétrica é um insumo industrial, mas também social.”. (D’ARAÚJO\&CASTRO, I997, p. 302)

19 Após o mandato do presidente Geisel em que Ueki foi ministro de Minas e Energia, no mandato de Figueiredo, Shigeaki Ueki foi presidente da Petrobrás.
} 


\section{C) GitistóñórICA}

econômico ${ }^{20 "}$, com elevação da inflação e redução dos investimentos. Apesar de termos a Petrobrás ${ }^{21}$ criada na década de 1950, quando o Brasil era governado por Getúlio Vargas e ela ser uma das empresas que possui maior distinção mundial, somente nos anos 2000, o Brasil alcançou a autossuficiência de petróleo, sendo necessária à sua importação naquele período a fim de suprir as necessidades nacionais.

A explanação feita acerca do princípio do Governo Geisel e também sobre a questão energética, a qual é deveras interessante para a compreensão do destaque dado pela imprensa à parceria entre Brasil e China. Lembrando que as informações que chegavam à imprensa vinham, na sua maioria, de fontes oficiais do Governo, conforme os periódicos costumam ressaltar; todavia ainda tivessem suas matérias fiscalizadas pelos censores que trabalhavam em prol do governo naquele período. Embora nenhum dos Atos, Tratados e Acordos entre Brasil e RPC utilizados nesta pesquisa trate sobre assuntos relacionados ao petróleo, na imprensa houve bastante repercussão à possível negociação da compra deste produto por parte do governo brasileiro. Entretanto, a abordagem realizada pelos periódicos aqui analisados difere uma da outra, o que é corrente, considerando que o público - fora as próprias fontes oficiais do Governo - não costuma ser o mesmo, apesar de não ter sido possível especificar quem eram os leitores destes jornais no presente artigo. Mas, não queremos com isso dizer que as informações foram manipuladas, no sentindo perverso que comumente se atribui à palavra, pois conforme Champagne,

Seria ingênuo acreditar que a imprensa produz, por si só, de forma totalmente arbitrária e manipuladora, os "acontecimentos". Na realidade, trata-se de uma produção coletiva: os jornalistas são apenas seus agentes mais visíveis e, ao mesmo tempo, os mais bem ocultos. Seja qual for a maneira, positiva ou negativa, como falam a respeito, existem "acontecimentos" que não podem deixar de ser relatados pelos jornalistas sob pena de dilapidarem seu capital de credibilidade; nem podem inventar seja lá o que for como "acontecimento" sob pena de perderem precisamente seu próprio poder de criação de eventos. É na relação entre o campo ${ }^{22}$ da

\footnotetext{
${ }^{20}$ Foi a denominação dada para o período do Governo Médici (1969-1973) em que a economia cresceu rapidamente.

${ }^{21}$ Antes de ser presidente da República, Geisel foi presidente da Petrobrás. Seu histórico na carreira política ainda inclui a refinaria de Cubatão e o Conselho do Petróleo.

${ }^{22}$ Um autor que aborda as noções de campo é Pierre Bourdieu, mas não aprofundaremos este conceito no decorrer deste trabalho.
} 


\section{G) Citustótórica}

imprensa e os diferentes campos sociais que se engendram os “acontecimentos”. (CHAMPAGNE, I996, p. 224)

Portanto, a forma com que o jornal produz o material a ser veiculado é que irá formando, com o tempo, a sua credibilidade informativa. O que se pode afirmar, em relação ao público, é que cada periódico possui leitores cativos ${ }^{23}$, estejam eles interessados em notícias sobre política, esporte, cultura ou outras temáticas. Partindo desta ideia e levando em consideração que os jornais se dizem representantes da chamada "Opinião Pública"24, um ponto que norteou o pensamento desta pesquisadora durante a "leitura flutuante" 25 nos periódicos selecionados foi que a realidade desta "opinião pública" é algo a ser questionado, pois, através da sua narrativa, pode-se perceber que há uma determinada tomada de posição frente às negociações que estavam surgindo entre o Brasil e a República Popular da China naquele momento, o que pode ser identificado através do uso de advérbios e adjetivos, por exemplo, na narrativa dos jornalistas que usam essa estratégia na tentativa de criar uma imagem específica ao leitor. Sendo assim, defende-se a ideia de que não há uma representação una por parte da imprensa que se diz defensora da "opinião pública”. Então, a quem estariam eles se referindo como "opinião pública"?

Para iniciar essa discussão, vamos refletir acerca do que foi veiculado sobre a relação entre o Brasil e a China comunista no período em que Geisel estava recém assumindo a administração do país. Sua posse ocorreu na metade do mês de março de 1974, como mencionamos anteriormente, e desde o início daquele mês os dois jornais já comentavam sobre o contato entre os países. O OESP publicou já no dia 7 de março uma nota ${ }^{26} \mathrm{com}$ informações segundo as quais, no mês seguinte, iria para a China uma missão comercial brasileira, com o intuito de "incrementar as vendas" para aquele país, o que estaria sendo considerado pela Associação de Comércio Exterior do Brasil (doravante, AEB) um mercado de "forte potencial". A nota ${ }^{27}$ acima desta informa sobre uma fala do ministro Delfim Netto $^{28}$

\footnotetext{
23 Ver: CHARADEAU, Patrick; 2013.

${ }^{24}$ CHAMPAGNE (I996) comenta sobre esta questão da mídia e a "opinião pública", ressaltando que "Por profissão, os jornalistas tornar-se-ão "líderes de opinião": exprimem sua opinião que pensam ser também a opinião de seus leitores e essa opinião pré-ajustada ao público, lida pelos leitores, tende a tornar-se a opinião dos leitores e, por consequência, um importante componente do que é percebido como "opinião pública"." p. $7 \mathrm{I}$

${ }^{25}$ Etapa própria da Análise de Conteúdo, na qual esta pesquisa se inspira.

26 "Economia - Missão", O Estado de São Paulo, 07 de março de 1974, p. 3.

27 "Economia - Exportação", O Estado de São Paulo, o7 de março de I974, p. 3.

${ }^{28}$ Delfim Netto desempenhou vários cargos no período da ditadura civil-militar, sendo Ministro da Fazenda (1967-1974) - período no qual ocorreu o AI-5 e tendo o nome do ministro como um dos seus assinantes -, Embaixador do Brasil na França (I974-I978), Ministro da Agricultura (I979) e Ministro do Planejamento (I9791985).
} 


\section{C) GitcastóricA}

que ocorreu na $\mathrm{AEB}$, na qual o destaque foi para o "papel decisivo das exportações para o fortalecimento do poderio nacional". Ambas as notas são complementares e remetem para notícias que discorrem sobre elas no interior do jornal, relacionando uma necessidade para o desenvolvimento, conforme a exposição do ministro, a uma possível solução preventiva que demonstra o fato de os exportadores já estarem atentos para a importância da questão, embora já ser habitual a um comerciante explorar suas possibilidades de melhora nos negócios.

A notícia ${ }^{29}$ à qual a nota fazia referência e com um título em letras garrafais no topo da página, indicava a China como sendo "a melhor alternativa para aumentar as exportações brasileiras", nas palavras do próprio presidente da AEB. No texto é ressaltado que Giuliete Coutinho "nada adiantou sobre a possibilidade" de um representante do governo integrar a missão, juntamente com os exportadores que iriam nesta viagem comercial, em caráter avaliativo. O Estadão assinala que o objetivo central da missão é "dar continuidade aos entendimentos" do ano anterior. Esta era a segunda missão comercial organizada pela AEB para a China, sendo que a primeira ocorreu em outubro de 1972, um ano após a China ter tido a sua entrada na ONU, tendo o Brasil votado contra ${ }^{30}$.

Já o Jornal do Brasil havia publicado, no dia anterior a esses textos do Estadão, uma notícia ${ }^{31}$ em editoria que versava sobre política e governo, e nesse texto o foco era sobre as visitações de cumprimentos ao General presidente que estavam ocorrendo por parte de autoridades governamentais e, principalmente, sobre os ministros que fariam parte do Governo Geisel e já estavam mantendo contato direto com o presidente. O ministro Azeredo da Silveira recebeu destaque nesta notícia em dois momentos, sobre o mesmo assunto. Primeiramente, havia o relato de todos que estiveram com Geisel no dia anterior, mencionando Silveira e, ao final desta primeira parte, segundo o escrito, ao ser questionado por um repórter sobre o reatamento da relação entre Brasil e China, o ministro respondeu que “ainda é cedo para pensar no assunto". Após falar sobre os outros visitantes e também informar que nenhum dos ministros daria informações sobre o futuro do Governo, o jornal volta a abordar sobre as questões de política externa, ressaltando adjetivos, como "delicado",

\footnotetext{
29 "Missão vai avaliar potencial chinês", O Estado de São Paulo, o7 de março de 1974, p. 46.

${ }^{30}$ Oscar Araripe é autor do livro "China Hoje - O Pragmatismo Possível", publicado em 1974. O livro possui uma cronologia ao final dele com todo o histórico das relações entre Brasil e China, em formato de linha do tempo, e nessa parte constam também estas informações sobre a primeira viagem da $\mathrm{AEB}$ e o voto contrário à entrada da China na ONU por parte do Governo brasileiro. Araripe foi jornalista e esteve presente na missão chefiada por Coutinho, que foi à China em abril de 1974, fato este melhor analisado em minha dissertação de mestrado. 31 "General Geisel recebe visita de mais oito no Largo da Misericórdia", Jornal do Brasil, 6 de março de 1974, p. 3, $I^{\circ}$ caderno.
} 


\section{C) GitcastóricA}

no sentido figurado, remetendo a algo que demanda cautela/prudência, e "complicado" que tem um de seus sentidos usado em tom pejorativo. Tais expressões foram empregadas no texto sobre um curto diálogo com Silveira ainda no dia 5 de março, que "também só quer falar depois do dia I5". É importante mencionar aqui que o primeiro adjetivo citado estava expresso nas palavras do ministro, sendo que o segundo constava na narrativa do próprio jornal acerca do assunto. A notícia é finalizada novamente com a alusão ao reatamento entre Brasil e China, sendo utilizada a palavra "secamente", que é um advérbio de modo, para definir a maneira com que Silveira respondeu aos jornalistas sobre a questão, dizendo que “é muito cedo para pensarmos nisso", como já dito anteriormente.

Ao analisar os textos dos jornais, constatamos que houve duas abordagens diferenciadas dadas ao assunto diplomático. O jornal O Estado de São Paulo deu destaque aos civis empenhados em seus negócios privados que igualmente trariam excelente retorno internacional ao Brasil, sem descartar ao mesmo tempo que ainda não havia confirmação pública sobre a participação governamental na missão brasileira, no início do mês de março. Já o Jornal do Brasil apostou em publicar informações diretamente das bases do governo sobre o reatamento da parceria entre os dois países e sobre o qual podemos perceber que, independente da questão, todos os ministros citados na reportagem não estavam tornando públicas as discussões que já ocorriam com o General Geisel sobre o governo. A AEB publicou entrevistas com alguns integrantes da missão que foi à China em abril de 1974, na ocasião da comemoração dos 40 anos da retomada de relações diplomáticas entre Brasil e China. Oscar Araripe ${ }^{32}$ foi um dos integrantes que concedeu entrevista e, ao ser questionado sobre como teriam obtido autorização para ingressar na China sem ter naquela época relações diplomáticas entre os dois países, Araripe respondeu que oficialmente não havia, mas que os dois países já estavam "se namorando".

Após esta notícia ${ }^{33}$ publicada no início do mês de março, o $J B$ não expôs, em suas pautas no decorrer do mês, o assunto sobre a parceria entre Brasil e China, bem como sobre a viagem dos exportadores que ocorreria no mês de abril. Porém, a China em si não ficou de

\footnotetext{
${ }^{32}$ Araripe diz que os preparativos para a viagem foram "intensos e tensos" e que a viagem foi algo bastante divulgado pela mídia; ressalta também que seu livro a respeito da viagem só foi publicado após o editor ter adicionado uma declaração do General Ernesto Geisel que data de I9 de março de I974. É interessante destacar que Oscar Araripe, apesar de ter ido na missão como "dono de jornal” por ser um dos proprietários do jornal inglês The Brazilian Gazette, trabalhava para o Jornal do Brasil e fornecia todas as suas ações para o JB. Disponível em: http://www.aeb.org.br/aeb45/noticia.asp?Id=I24, acesso em: 20/oI/20I9. Após procurar a informação do período em que ele esteve ligado ao $J B$ e não localizar a informação nas redes, procurei entrar em contato com o autor, o qual me retornou via e-mail com a informação de que trabalhou no JB de 1970 a 1975.

33 "General Geisel recebe visita de mais oito no Largo da Misericórdia", Jornal do Brasil, 6 de março de I974, p. 3, $\mathrm{I}^{\mathrm{o}}$ caderno.
} 


\section{C) Hitsoa}

fora das publicações do jornal. O país comunista foi mencionado, em quase todos os dias do mês, na editoria que trata sobre as questões internacionais. Apesar de conter vários textos sobre os problemas entre os chineses e soviéticos - problema que aparece em ambos jornais durante todo o ano de $1974-$, é interessante ressaltar que houve notícias em que a narrativa empregada colocava a China em posição de destaque no meio internacional e de forma positiva, ao falar sobre sua produção de petróleo, bem como do seu poderio como país exportador ${ }^{34}$. Ainda sobre esse assunto, foi publicado um artigo assinado 35 escrito por Theodoro Shabad, articulista do The New York Times no qual se analisa quem estaria lucrando com a "crise mundial de energia", apontando as investidas chinesas e soviéticas para desenvolver as exportações. Também é informado sobre a possibilidade de viajar de avião do Canadá para a China ${ }^{36}$, assim como há diversas propagandas sobre pacotes de viagem turística ${ }^{37}$ do Brasil para a RPC. Outra curiosidade é o aparecimento da expressão "negócio da china"38 utilizada para referir-se a algum produto que estaria sendo comercializado. Acerca das relações entre Brasil e China, o jornal volta a tocar no assunto somente no dia 25 de março de 1974 , em uma pequena nota ${ }^{39}$ no Caderno B, registrando que, se a missão comercial realmente fosse à China no mês de abril, o ex-ministro da fazenda Delfim Neto também estaria presente em virtude de ter assumido um novo cargo junto à Associação Nacional dos Exportadores.

Ao contrário do jornal carioca, o Estadão publicou uma notícia ${ }^{40}$ ainda antes do dia 15 de março, discorrendo sobre o novo estilo da política externa brasileira e caracterizando Azeredo da Silveira como alguém que tem "a experiência de negociador". Ainda que a temática central do texto fosse relacionada à nova diplomacia de forma geral, o título que ocupava o topo da página remetia à aceitação do Itamaraty quanto a ida à China mas, já no primeiro parágrafo, há a informação de que "poderá conter um observador governamental", não estando ainda confirmada a decisão. Destaca ainda que, conforme Silveira, a possível aproximação dos dois países seria em função de atender a interesses nacionais, ao mesmo tempo em que ocorre a defesa de que, se isso se concretizasse, estaria marcando um novo rumo dentro da política de comércio exterior empregada pelo Itamaraty, assinalando mais

\footnotetext{
34 "EUA falam da China como grande exportador", Jornal do Brasil, I6 de março de I974, p. 7, Iº caderno.

35 "Os que lucram com a crise de energia", Jornal do Brasil, I8 de março de 1974, p. 2, $\mathrm{I}^{\circ}$ caderno, artigo de Theodoro Shabad, do The New York Times.

36 "Vôos ligarão o Canadá à China", Jornal do Brasil, I6 de março de 1974, p. 8, $\mathrm{I}^{\circ}$ caderno.

37 "CHINA", Jornal do Brasil, 2I de março de I974, p.2, Iº caderno.

38 "Negócio da China”, Jornal do Brasil, II de março de 1974, p. 3, caderno B.

39 Jornal do Brasil, 25 de março de I974, p. 3, caderno B, coluna Vaivém.

40 "Itamaraty aceita ida à China", O Estado de São Paulo, I4 de março de 1974, p. 25.
} 


\section{C) HitsistóricA}

uma vez o caráter entusiasta, neste período, com a parceria entre Brasil e RPC. Com exceção desta notícia, o jornal OESP só voltaria a abordar a questão de uma possível retomada de relações, bem como a respeito da missão comercial brasileira, no final de março assim como o fizera o JB. Fora isso, houve matérias na editoria de internacional sobre a China e sua relação com os demais países, do mesmo modo que o jornal carioca também publicara.

O Jornal do Brasil pronunciou-se, no Informe J $B^{41}$ do dia 29 de março, a respeito da missão comercial, quando "brevemente" o Brasil e a China comunista incrementariam suas relações comerciais com um caráter "sério" e de "alto nível", podendo daí resultar em "relações diplomáticas entre Pequim e Brasília"42. No dia seguinte, estava, na capa do $J B^{43}$, informação da sucursal de Brasília, segundo a qual o Itamaraty havia decidido enviar representante do Governo, integrando a missão comercial de Coutinho e ressaltava que era a primeira vez que isso ocorria desde que na China foi implantado o "regime comunista". O que causa estranhamento é o fato de o jornal ter publicado esta notícia na capa, mas não conter nada no interior do jornal que apresentasse continuidade ao assunto, considerandose que a capa de um periódico é a sua vitrine, local em que ele convida o leitor para folhear suas páginas e conferir o conteúdo.

Bourdieu (1982), que defende a não existência da dita "opinião pública”, ao falar sobre a ineficácia das sondagens de opinião por contar com questões insuficientes para de fato gerar uma "opinião pública", pois, segundo ele, deve levar-se em conta quem encomenda uma sondagem e as não respostas por parte dos entrevistados. Considerando-se o ponto de vista do autor, a questão da falta de desenvolvimento do jornal acerca da diplomacia envolvendo Brasil e China conduz a estes questionamentos: haveria por trás desta questão quem encomendasse a notícia? Ou o contrário, quem não desejasse a sua publicação e tivesse poder suficiente para conseguir isso? Trata-se de um momento em que a interferência do governo federal ultrapassava a esfera pública, em virtude da censura, como já vimos, assim como mencionamos o fato de que as informações já chegavam filtradas para os jornalistas e, quando há o silêncio do jornal, questões como estas chamam a atenção. No mês de março, não houve mais nenhuma publicação no $J B$ sobre a relação entre Brasil e China.

\footnotetext{
$4 \mathrm{I}$ “Brasil- China”, Jornal do Brasil, 29 de março de I974, p.Io, Iº caderno, coluna Informe JB.

$4^{2}$ Idem.

43 "Brasil manda pela I ${ }^{\mathrm{a}}$ vez diplomata em missão à China", Jornal do Brasil, 30 de março de I974, capa.
} 


\section{C) Hitstơ}

Assim como o jornal carioca, o Estadão também publicou na capa ${ }^{44}$ do dia 30 sobre a oficialização da missão brasileira que estaria para embarcar para a China nos dias que seguiriam. A chamada remete a "pormenores" na editoria ${ }^{45}$ sobre assuntos internacionais, um texto da sucursal de Brasília, estando o título do artigo, como de praxe visto até então com as matérias envolvendo a temática desta pesquisa, ocupando toda a extensão do topo da página. $\mathrm{O}$ artigo exalta o caráter inovador desta decisão que faz parte de uma política "sem preocupação ideológica" que visava a incrementar o comércio com a "China comunista", podendo trazer "pela primeira vez" um "relatório oficial" sobre a receptividade que os chineses dariam para o gesto de "aproximação comercial" do Brasil. Após um início de certa forma elogioso à decisão do Itamaraty em enviar três funcionários de "alto escalão" na companhia dos empresários, o jornal comenta sobre o mistério feito em torno desta tomada de decisão, ao dizer que

Nas últimas semanas, áreas diplomáticas e econômicas afirmaram, por diversas vezes, que a missão brasileira teria caráter particular, seria integrada somente por empresários e dela não faria parte nenhum funcionário do governo, embora ressaltassem que isso absolutamente não significava que o Itamaraty não estivesse interessado no potencial econômico chinês. ${ }^{46}$

Para então concluir no mesmo texto que esta seria a razão, conforme "fontes ligadas às duas áreas", para acreditar que o Governo estaria interessado em acelerar o processo de reaproximação entre os dois países. Ao que se pode interpretar, o jornal está se referindo especificamente à relação diplomática entre ambos, pois, no dia seguinte, o Estadão publicou uma notícia, enaltecendo a importância em reconhecer o poderio chinês. Nesta notícia ${ }^{47}$, o jornal expressa com todas as letras que "a médio prazo" o Brasil estará reconhecendo diplomaticamente a China, fazendo uso do que foi dito por Geisel e Silveira sobre as novas diretrizes do governo na ocasião da posse para justificar esta impressão. Na sequência, o OESP apresentou o diplomata Carlos Antônio Bettencourt Bueno, um dos três integrantes selecionados pelo governo para participar da missão, como sendo um "especialista na China comunista" e fazendo uso de algumas de suas falas acerca da China em outras ocasiões que antecederam seu conhecimento de que integraria a missão, para descrever ao leitor que

\footnotetext{
44 “Oficializada missão a Pequim”, O Estado de São Paulo, 30 de março de 1974, capa.

45 "Missão do Brasil na China”, O Estado de São Paulo, 30 de março de I974, p. I7.

${ }^{46}$ Grifos meus. Todas as marcações em negrito neste trabalho foram feitas pela autora deste artigo, com a finalidade de ressaltar aspectos do texto que são importantes para a análise narrativa.

47 "Reconhecer China, o novo passo", O Estado de São Paulo, 3I de março de I974, p. 39.
} 


\section{C) GitcastórRICA}

reconhecer o mercado chinês faz parte do novo jogo político, sendo uma necessidade ao país que não quiser "abdicar de qualquer pretensão em termos mundiais".

Através da análise desses textos, pode-se constatar que, quinze dias antes e após a posse do General Ernesto Geisel na presidência do Brasil, nos jornais selecionados, houve uma postura investigativa de ambos na esfera pública perante as falas e informações que vinham dos setores governamentais. Tal postura foi por vez apresentada de maneira sutil, provavelmente no intuito de evitar a ação dos censores, mas que também conseguiu dar tônica à narrativa empregada. Além disso, foi possível perceber que a objetividade segundo a influência do jornalismo norte-americano não se sobrepôs à atuação do modelo opinativo francês. Será possível observar que a tônica das publicações permanece no mesmo caminho, contudo oscila em relação aos interesses que cada periódico defenderá em nome da dita “opinião pública”.

\section{Considerações finais}

Com base nos apontamentos realizados ao longo deste artigo, foi possível atingir o objetivo de identificar, através dos periódicos analisados, o princípio do enquadramento por eles realizado diante da parceria diplomática que se delineava no Brasil no governo Geisel (1974-1979) e, ainda, compreender qual a intenção do Governo brasileiro ao estabelecer relações diplomáticas com a China comunista naquele período. De fato, como visto nos textos jornalísticos e se pensou desde o princípio desta pesquisa, o caráter embrionário da relação entre Brasil e China comunista em 1974 se mostrou ser mais do que apenas uma relação comercial dentro da pauta da política externa. Considera-se, ainda, que o termo de estratégia relacionado à parceria na década de 1990 poderia ser referência do seu período embrionário.

Tal proposição é construída e defendida com base no que foi mencionado ser a definição de estratégia, que trata da aplicação eficaz do que se dispõe como recurso, explorando as condições favoráveis possíveis de desfrute, almejando alcançar determinados objetivos. Conforme exposto ao longo da dissertação de mestrado defendida por esta autora no início de 2019, a qual faz parte o assunto abordado neste artigo, o propósito central das relações externas era o desenvolvimento nacional. Através do exame das publicações dos jornais, os quais mostraram o desenrolar das negociações, nota-se que a China comunista se inseria adequadamente no processo de consolidação da parceria, pois possuía para a venda 


\section{C) GitistóñórICA}

um item tão caro ao Brasil, o petróleo. Além disso, tinha grande interesse em comprar o açúcar brasileiro, situação interessante ao Brasil devido à grande necessidade que os exportadores brasileiros tinham em conquistar novos mercados. Ainda, havia o intuito de desenvolver as exportações industriais brasileiras como um todo.

Assim se sabe, em relação à esfera pública, que havia nela interferências por parte do Governo, tendo em vista a prática da censura, por exemplo, mas também controlando o que iria para a imprensa, além de o que iria dela para o público. Porém, também ocorria a interferência do setor empresarial, em forma de entrevistas e palestras que eram mencionadas nas páginas dos jornais, dando margem para que seus interesses fossem divulgados através da imprensa, renovando o poderio contido na mídia como um vetor social e como possível responsável em ditar uma agenda.

\section{Referências:}

AQUINO, Maria Aparecida de. Censura, Imprensa e Estado autoritário (1968-1978): o exercício cotidiano da dominação e da resistência: O Estado de São Paulo e Movimento. Bauru: EDUSC, 1999.

ARARIPE, Oscar. China Hoje - O Pragmatismo Possível. Ied. Rio de Janeiro: Editora Artenova, 1974.

BECARD, Danielly Silva Ramos. O Brasil e a República Popular da China: política externa comparada e relações bilaterais (1974-2004). Brasília: FUNAG, 2008.

BERGER, Cristha. Toda a notícia que couber, o leitor apreciar e o anunciante aprovar, a gente publica. In.: MOUILLIAUD, M (org.) O Jornal: forma e sentido. Brasília: Paralelo I5, 1997. P. 273-284.

BOURDIEU, Pierre. A Opinião Pública Não Existe. In: THIOLLENT, Michel J. M. Crítica Metodológica, Investigação Social \& Enquete Operária. Belo Horizonte: Editora Polis, I987.

CAPELATO, Maria Helena Rolim; PRADO, Maria Ligia. O Bravo Matutino: Imprensa e Ideologia: O Jornal o Estado de São Paulo. São Paulo: Editora Alfa-Ômega, I98o.

CAPELATO, Maria Helena Rolim. Imprensa e História do Brasil. São Paulo: Editora Contexto/EDUSP, 1988. 


\section{C) GitistóñórICA}

CHAMPAGNE, Patrick. Formar a opinião: o novo jogo político. Tradução: TEIXEIRA, Guilherme J. de Freitas. Petrópolis, RJ: Vozes, I996.

CHARAUDEAU, Patrick. Discurso das Mídias. Tradução: CORRÊA, Ângela M. S. São Paulo: Editora Contexto, 2006.

D'ARAUJO, Maria Celina; CASTRO, Celso Corrêa Pinto de. Ernesto Geisel. Rio de Janeiro: Editora Fundação Getúlio Vargas, 1998.

. Dossiê Geisel. Ied. Rio de Janeiro: Editora FGV, 2002.

DOMINGOS, Charles Sidarta Machado. O Brasil e a URSS na Guerra Fria: a política externa independente na imprensa gaúcha. Porto Alegre: Suliani Letra \& Vida Editora, 20 Io. FERNANDES, Thomas Dreux Miranda. Diplomacia militar - Antônio Francisco Azeredo da Silveira: autonomia e interferências, o Itamaraty e o regime militar 1974-I979. Dissertação de Mestrado. São Paulo: USP, 2016.

HABERMAS, Jürgen. Mudança estrutural da esfera pública: investigações quanto a uma categoria da sociedade burguesa. Rio de Janeiro: Tempo Brasileiro, I984.

KRILOW, L. S. W. Cidades de papel: as representações sobre as favelas na imprensa carioca durante o segundo governo Vargas (I95I-I954). Dissertação de mestrado. Porto Alegre: PUCRS, 2018.

LAFER, Celso. A identidade internacional do Brasil e a política externa brasileira: passado, presente e futuro. São Paulo: Perspectiva, 200I.

LIGIÉRO, Luiz Fernando. A autonomia na política externa brasileira: a política externa independente e o pragmatismo responsável: momentos diferentes, políticas semelhantes? Brasília: Fundação Alexandre de Gusmão, 20II.

LIPPMANN, Walter. Opinião pública. [2. ed.] Petrópolis, RJ: Vozes, [20IO].

LUCA, Tânia Regina de. História dos, nos e por meio dos periódicos. In: PINSKY, Carla Bassanezi (Org.). Fontes Históricas. São Paulo: Contexto, 2005.

MARTINS, Luis Carlos dos Passos. História dos Conceitos e Conceitos na História: a imprensa como fonte/objeto na História dos Conceitos Políticos. In: Charles Sidarta M. Domingos, Alessandro Batistella e Douglas Souza Angeli. (Org.). Capítulos de história política. Ied.São Leopoldo: OIKOS, 20I8, v. I, p. 53-74. 


\section{C) Hitcas TórICA}

MORAES, Roque. Análise de conteúdo. Revista Educação, Porto Alegre, v. 22, n. 37, p. 7-32, 1999.

OLIVEIRA, Henrique Altemani; LESSA, Antônio Carlos (Org.). Relações Internacionais do Brasil: temas e agendas. v.I. São Paulo, Saraiva: 2006.

Brasil e China: uma nova aliança não escrita? Revista Brasileira de Política Internacional, v. 53, p. 88-I06, 2010.

. Brasil-China: 30 anos de uma parceria estratégica. Revista Brasileira de Política Internacional, v. 47, n. I, p. 7-30, 2004.

PEREIRA, Lia Valls. Relações comerciais Brasil-China: um parceiro especial? Cadernos Adenauer, Rio de Janeiro, v.7, n.I, p.II7-I27, 2006.

PINHEIRO, Letícia de Abreu. Política externa brasileira, I889-2002. Rio de Janeiro: Jorge Zahar Ed., 2004.

. O pragmatismo responsável no arquivo do presidente Geisel. In: D’ARAUJO, Maria Celina; CASTRO, Celso Corrêa Pinto de (org.). Dossiê Geisel. Rio de Janeiro: Editora FGV, 2002. p. $75-88$.

RIBEIRO, Ana Paula Goulart. Imprensa e História no Rio de Janeiro dos anos I950. Rio de Janeiro: E-papers, 2007.

SOARES, G. A. D. Censura durante o regime autoritário. Revista Brasileira de Ciências Sociais (Impresso), v. IO, p. -, I995.

VIZENTINI, Paulo Gilberto Fagundes. A novíssima China e o Sistema Internacional. Revista de Sociologia e Política [impressa], v. I9, p. I3I-I4I, 201 I.

. A Projeção Internacional do Brasil 1930-2012: diplomacia, segurança e inserção na economia mundial. I. ed. Rio de Janeiro: Elsevier, 2013.

A política externa do regime militar brasileiro. 2. ed. Porto Alegre: Editora da UFRGS, 2004. p. I67-269.

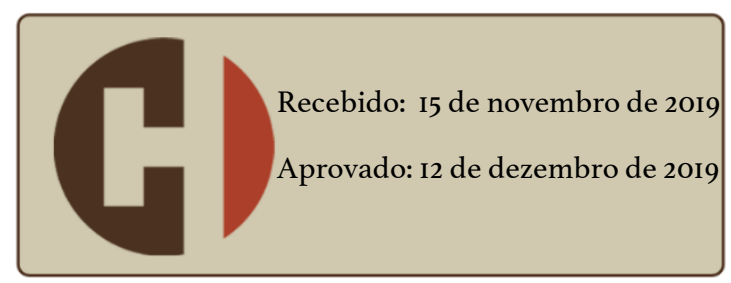

